\title{
NOÇÃO DE CIDADANIA É SECUNDÁRIA NAS QUESTÕES DE CIÊNCIAS DA NATUREZA DO ENEM
}

http://dx.doi.org/10.5902/2318133864033

\author{
Rodrigo Bastos Cunha ${ }^{1}$
}

\begin{abstract}
Resumo
O Exame Nacional do Ensino Médio - Enem -, usado no processo seletivo de diversas universidades, tem influência na etapa do ensino avaliada nessa prova. A noção de cidadania é central nas pesquisas sobre ensino CTS e sobre letramento científico. O objetivo deste artigo é analisar as questões de Ciências da Natureza do Enem 2019, sob a ótica de três categorias de letramento em Ciências propostas por Shen (1975) e duas visões conflitantes de letramento científico apontadas por Roberts (2007), para ver se a noção de cidadania está ou não no foco do que das questões da prova. A análise mostrou que a noção de cidadania é secundária nesta prova e são poucas as questões que demandam conhecimento prático ou cívico em Ciências.

Palavras-chave: Enem; ensino CTS; letramento científico.
\end{abstract}

\section{THE NOTION OF CITIZENSHIP IS SECONDARY IN QUESTIONS OF NATURAL SCIENCES OF ENEM}

\begin{abstract}
The National High School Exam, used in the selection process of several universities, has a great influence on the teaching stage evaluated in this test. The notion of citizenship is central to research on STS teaching and scientific literacy. The purpose of this paper is to analyze the nature sciences questions of Enem 2019, from the perspective of three categories of science literacy proposed by Shen (1975) and two conflicting views of scientific literacy pointed out by Roberts (2007), to see if the notion of citizenship is in the focus of what is assessed or not. The analysis shows that the notion of citizenship is secondary in this test and there are few questions that require practical or civic knowledge in science.

Key-words: Enem; STS teaching; scientific literacy.
\end{abstract}

1 Universidade Estadual de Campinas, Brasil. E-mail: rbcunha@unicamp.br. 


\section{Introdução}

s pesquisas sobre ensino de Ciências pautadas nas relações entre ciência,
tecnologia, sociedade - CTS - têm pelo menos meio século de contribuições e
uma crescente participação de educadores brasileiros a partir da década de 1990. Entre os objetivos de toda essa discussão acadêmica estão mudanças nos cursos de formação de professores, nos materiais didáticos e na própria sala de aula, para que o ensino de Ciências seja mais significativo para os estudantes e que faça parte de sua formação como cidadãos conhecer os impactos positivos e negativos do desenvolvimento científico e tecnológico e a influência da sociedade sobre novas demandas de conhecimento em ciência e tecnologia.

No caso específico do ensino médio, por maiores que sejam os esforços de mudança nos cursos de formação de professores, por melhores que sejam as edições mais atuais de livros didáticos, por mais que se tente inserir nas salas de aula debates sobre temas sociais com algum componente científico e tecnológico, sabe-se que a maior parte da carga horária das disciplinas de Ciências Naturais é dedicada à preparação dos alunos para os exames de acesso ao ensino superior, sejam os vestibulares, seja o Exame Nacional do Ensino Médio - Enem -, usado no processo seletivo de diversas instituições, como as universidades federais. Isso significa que se os vestibulares e o Enem incorporam as contribuições das pesquisas acadêmicas, em termos de mudança no tipo de conhecimento a ser cobrado nas provas, a chance d'essas mudanças chegarem às salas de aula é maior.

Santos e Mortimer (2001) estabelecnuma relação direta entre o ensino CTS e a noção de letramento científico e tecnológico: "O principal objetivo de currículos CTS é o letramento científico e tecnológico para que os alunos possam atuar como cidadãos, tomando decisões e agindo com responsabilidade social" (p. 95). Segundo eles o "letramento científico e tecnológico necessário para os cidadãos é aquele que os prepara para uma mudança de atitude pessoal e para um questionamento sobre os rumos de nosso desenvolvimento científico e tecnológico" (p. 107).

Como ensino CTS e letramento científico têm essa inter-relação, serão mencionados, a seguir, alguns pressupostos do ensino CTS e estudos que estabelecem relação entre esses pressupostos e o Enem. Em seguida serão apresentadas três categorias de letramento científico - prático, cívico e cultural - propostas por Shen (1975) ${ }^{2}$ e duas visões conflitantes no ensino de ciências sobre letramento científico na avaliação de Roberts $(2007)^{3}$. O objetivo deste artigo é apresentar o resultado da análise das questões da prova de ciências da natureza e suas tecnologias do Enem 2019, usando como metodologia a classificação dessas questões sob a ótica das categorias de Shen (1975) e das visões conflitantes de ensino de ciências observadas por Roberts (2007).

\footnotetext{
${ }^{2}$ A noção de letramento científico passou por diversas interpretações desde que surgiu, no final dos anos 1950. As categorias propostas por Shen (1975) são amplamente aceitas e usadas até hoje em diversos trabalhos no mundo inteiro, inclusive no Brasil, por sua simplicidade e elegância.

${ }^{3} \mathrm{O}$ trabalho em que Roberts (2007) apresenta as duas visões conflitantes de letramento científico é uma ampla e rigorosa revisão de publicações em língua inglesa sobre o tema por autores de vários países. 


\section{Os objetivos do ensino CTS}

Quem viveu os anos de chumbo no Brasil sabe bem o que significa a luta envolvendo a noção de cidadania. A Constituição Federal, promulgada em 1988, já associava essa noção ao ensino, em seu artigo 205: "A educação [...] será promovida [...] visando [...] preparo para o exercício da cidadania" (Brasil, 1988). Essa noção se mantém no artigo $2^{\circ}$ da Lei de Diretrizes e Bases da Educação (Brasil, 1996) e se desdobra no item Escola e constituição da cidadania do capítulo dos Parâmetros Curriculares Nacionais dedicado a seus princípios e fundamentos (Brasil, 1997).

Alves (2011, p. 86) afirma que "um dos principais objetivos do enfoque CTS/CTSA 4 é a formação para a cidadania". Essa formação está diretamente relacionada a uma participação ativa na sociedade, pois "outro objetivo da educação CTS/CTSA é desenvolver nos educandos a capacidade de tomada de decisões e a formação de valores" (p. 35). Os juízos de valor e as decisões estão relacionados a atitudes. Segundo Santos e Schnetzler (1997, p. 59), o "ensino CTS está vinculado à educação científica do cidadão" e é caracterizado "pela organização conceitual centrada em temas sociais, pelo desenvolvimento de atitudes de julgamento" (p. 64). Para eles, ao se considerar "o objetivo de formação do cidadão, pode-se destacar que os cursos que mais se enquadram em tal perspectiva são os que dão maior ênfase aos aspectos sociais da ciência e da tecnologia" (p. 67).

Que temas sociais ou aspectos sociais da ciência e da tecnologia seriam esses? Em que sentido se fala em formação de valores, tomada de decisões e participação ativa na sociedade? Alves (2011) cita decisões individuais de cada sujeito, como "separar o lixo para reciclagem ou não, optar pelo transporte público ou ir de carro para o trabalho", e decisões políticas e coletivas, como "apoiar ou não a construção de usinas nucleares, o investimento em fontes renováveis de energia, a produção e consumo de transgênicos" (p. 34). Mascio (2009) menciona tomada de decisões "em relação à escolha de alimentos, uso da eletricidade, consumo de água", ligadas ao nosso comportamento como consumidores, e à "escolha do candidato num cargo político" (p. 34) que fazemos como cidadãos. Ele acrescenta que "na orientação CTS são tratadas problemáticas socioambientais com base em conceitos da ciência e da tecnologia, e são levantadas questões sobre as implicações sociais do desenvolvimento científico e tecnológico" ( $p$. 35).

Se, por um lado, é crescente o protagonismo da ciência e da tecnologia nos modos de produção da sociedade capitalista desde a Revolução Industrial, por outro lado, sua imagem nunca mais foi a mesma depois das bombas de Hiroshima e Nagasaki. Ferreira (2011) lembra que "mitos em relação ao desenvolvimento científico e tecnológico começaram a ser questionados a partir da década de 1950 e mais evidentemente na década de 1960" (p. 19) e esses questionamentos foram impulsionados "por uma série de desastres ambientais e sociais que colocavam em evidência a afetação direta da ciência e

${ }^{4}$ Cavalcanti, Costa e Chrispino (2014, p. 35) observam que pesquisadores do Canadá e de Israel acrescentaram a letra E, de environment, na sigla STS, "para destacar as interações que repercutiam diretamente no meio ambiente". Desde então também se usa a expressão ensino CTSA no Brasil.

Regae: Rev. Gest. Aval. Educ. $\quad$ Santa Maria

v. 10

n. 19

e64033 p. 1-22 2021 
da tecnologia no bem estar da natureza e da sociedade". Ferreira (2011, p. 20) defende que as "críticas, os dilemas, as vantagens e desvantagens em relação a produção e ao uso da ciência e da tecnologia devem ser colocados em evidência e fazer parte de uma educação" com perspectiva CTS.

\section{Enfoque CTS e o Enem}

Segundo Santos (2007), no capítulo dos Parâmetros Curriculares Nacionais do Ensino Médio dedicado às Ciências Naturais, "há uma nítida proposição curricular com enfoque CTS, que surge com a denominação de contextualização", a qual, além de situar ciência e tecnologia do ponto de vista histórico, social e cultural, propõe "a discussão de aspectos práticos e éticos da ciência no mundo contemporâneo" (p. 482). Para Ferreira (2011), o objetivo da contextualização é "trazer significados à vida do aluno, aproximando o contexto escolar da sua realidade, a fim de lhe conferir a possibilidade de traçar relações entre teoria e prática, estabelecer relações entre sua vida cotidiana e os componentes curriculares da escola" (p. 11).

De acordo com Mascio (2009, p. 18), nas diretrizes curriculares nacionais para o ensino médio, "a contextualização é definida como uma situação de aprendizagem, na qual o conhecimento é transposto da situação em que foi criado, inventado ou produzido, relacionado com a prática ou a experiência do estudante, a fim de adquirir significado". Alves (2011) observa que a prova do Enem, de acordo com o Instituto Nacional de Estudos e Pesquisas Educacionais, responsável por sua aplicação, "inclui a interdisciplinaridade e a contextualização dos fatos, colocando o estudante frente a situações-problema de circunstâncias cotidianas e valorizando sua autonomia para fazer escolhas e tomar decisões" (p. 24).

Em sua análise da prova de Ciências da Natureza do Enem 2009, Alves (2011) pondera que outra "maneira de se visualizar a contextualização é observando se ela foi trazida apenas para ilustração dos conhecimentos científicos ou se requisitou ao candidato uma tomada de atitudes numa perspectiva de transformação da realidade" ( $p$. 104) Segundo ela apenas seis questões daquela prova envolviam esse último aspecto. Do ponto de vista de Alves (2011), uma vez que os elaboradores da prova entendem a contextualização apenas como ilustração do conhecimento científico, "talvez esteja se perdendo a oportunidade de utilizar aqueles exemplos do dia a dia de uma maneira na qual os alunos se sintam como potenciais transformadores daquela realidade" (p. 27).

\section{Metodologia}

Serão apresentadas, a seguir, as três categorias de letramento científico propostas por Shen (1975) e as duas visões conflitantes de letramento científico que, segundo Roberts (2007), são inerentes ao ensino de Ciências, as quais serão usadas para classificar as questões da prova de Ciências da Natureza do Enem aqui analisadas. Essas categorias e visões também serão o parâmetro a ser utilizado para verificar o quanto os temas sociais envolvidos na noção de letramento científico e nos pressupostos do ensino CTS estão contemplados nessas questões do Enem. 
1) Temas sociais no letramento científico

No contexto do pós Segunda Guerra Mundial começou-se a discutir a noção de letramento científico no campo da educação e do ensino de Ciências. Em mais de meio século de discussões não há consenso em torno dela, mas entre as definições mais aceitas estão as categorias sugeridas por Shen (1975): quanto mais simples a descrição de um fenômeno complexo, melhor. Ele considerou útil "distinguir três formas de letramento em ciência, que diferem entre si não apenas em seus objetivos, mas muitas vezes também em seu público, conteúdo, formato e modo de distribuição"5 (p. 265).

A primeira delas seria o letramento prático em ciência, que ele define como "a posse de um tipo de saber científico e técnico que possa ser colocado em uso imediatamente para ajudar a melhorar padrões de vida" (p. 265), envolvendo temas como alimentação e saúde. Shen (1975) comentou o papel da comunicação de massa na disseminação desse tipo de conhecimento. Um exemplo recente são os cuidados básicos de higiene no enfrentamento da pandemia do coronavírus.

A segunda categoria, que Shen (1975) chamou de letramento cívico em ciência, envolve políticas públicas que afetam o cidadão, relacionadas a ciência e tecnologia, em diversas áreas: "saúde, energia, alimentos e agricultura, recursos naturais, meio ambiente, [...] comunicação, transportes" (p. 266). De acordo com Shen (1975) o objetivo do letramento cívico em ciência é tornar o cidadão mais consciente sobre temas relacionados à ciência "para que ele e seus representantes possam [...] participar de forma mais completa do processo democrático numa sociedade cada vez mais tecnológica" (p. 266).

Segundo ele, "o processo de tomada de decisão numa típica questão pública relacionada à ciência" requer que "os possíveis riscos e benefícios de uma ação proposta sejam avaliados" e "a decisão política sobre realizar ou não a ação é tomada com base na tabela de risco-benefício" (p. 266). Um exemplo disso foi dado pelo então secretário de Ciência, Tecnologia e Insumos Estratégicos do Ministério da Saúde ao explicar, em abril de 2020, a decisão de recomendar o uso da cloroquina apenas para os casos mais graves de covid-19, para os quais os benefícios seriam maiores que os riscos, sendo necessários mais estudos para garantir a segurança de se estender essa recomendação para os casos mais leves. Do ponto de vista do cidadão a decisão sobre apoiar ou não as medidas de isolamento, decretadas em nível municipal e estadual, envolvia conhecimento mínimo sobre os benefícios do isolamento no achatamento da curva de crescimento do número de casos confirmados e de mortes por covid-19 - diante dos custos econômicos da momentânea paralisia dos negócios - e os riscos de não se adotar o isolamento para manter a atividade econômica, como o aumento exponencial de casos por covid-19 e o possível colapso no sistema de saúde.

A terceira forma de letramento em ciência seria o cultural, "motivado pelo desejo de saber algo sobre ciência como uma grande conquista humana" (Shen, 1975, p. 267). Para ilustrá-la Shen (1975) diz que "quando um artista lê uma matéria sobre DNA numa revista ou um advogado assiste a um programa de TV sobre a Nebulosa do Caranguejo, eles estão ocupados em melhorar seu letramento cultural em ciência" (p. 267). Segundo Shen (1975) "eles o fazem com o mesmo espírito com que um estudante de ciência pode

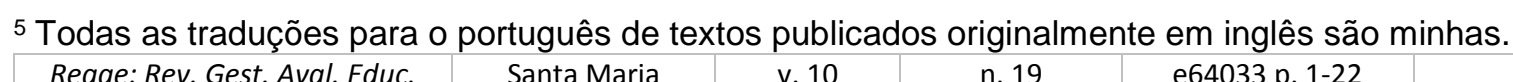


estudar história antiga, um engenheiro ler poesia ou um físico se deleitar com tragédias clássicas" (p. 267). Qualquer leigo que se interessasse, por exemplo, em assistir à série Pandemia, lançada pelo Netflix em 2020, ou ao episódio A próxima pandemia, da série Explicando, lançado em 2019, o faria para ampliar seu repertório cultural em matéria de ciência.

Embora essas categorias de Shen (1975) sejam amplamente aceitas, certamente não são unanimidade. A falta de consenso em torno da definição de letramento científico, segundo Roberts (2007) está ligada a "uma contínua tensão política e intelectual que sempre foi inerente à própria educação científica" ( $p$ 730). Ele se refere "ao papel de duas fontes curriculares legítimas, mas potencialmente conflitantes: a matéria ciência importa por si, e situações nas quais a ciência pode ser legitimamente vista como tendo um papel em outros assuntos humanos" (p. 730). A primeira que ele chamou de Visão I, "dá sentido ao letramento científico olhando para dentro do cânone da ciência natural ortodoxa, isto é, para os produtos e processos da própria ciência" (p. 730). A segunda, Visão II, deriva o significado de letramento em ciência "de situações com um componente científico, que os estudantes provavelmente encontrarão como cidadãos" (p. 730).

De acordo com Roberts (2007), em ambos os grupos, as definições de letramento científico, com poucas exceções, concentram-se em identificar qual conhecimento seria válido para os estudantes ao longo da vida, "independentemente de suas preferências e aspirações de carreira" (p. 740). Isso significa que "o ensino de ciências precisa, de alguma forma, resolver os problemas associados à educação de dois grupos de estudantes muito diferentes (pelo menos dois)" (p. 752): os que vão seguir carreira científica, uma minoria, e todos os demais. Como seria, portanto, o currículo de ciências destinado a promover o letramento científico para ambos os grupos?

Segundo Roberts (2007) a percepção pública da ciência e o letramento cívico em ciência do público adulto "são manifestos em situações específicas; portanto, o conhecimento científico que as pessoas empregam nessas situações é contextualizado de acordo com o que a situação requer" (p. 781). Ele menciona a noção de ciência para fins sociais específicos, para a qual é fundamental "a rejeição do tão conhecido 'déficit cognitivo' no entendimento de letramento científico em favor de um modelo mais interativo" (p. 782), no qual todas as formas de conhecimento - uma delas a ciência - são valorizadas. Para ele, isso "não é dizer que o conhecimento científico não seja importante. É, no entanto, salientar a importância de tomar a situação como ponto de partida, e não o cânone científico em si” (p. 783).

\section{Resultados}

O Enem foi criado em 1998 com o objetivo de "não somente avaliar o ensino médio no país, mas também, fornecer um instrumento que pudesse influenciar na reestruturação curricular da educação básica" (Alves, 2011, p. 14). Até 2008 a prova era realizada num dia e tinha 63 questões de múltipla escolha e uma redação dissertativo-argumentativa. Em 2009, quando o Ministério da Educação abriu a possibilidade de universidades e institutos federais aderirem ao uso do Enem em seus processos seletivos, a prova foi reformulada e passou a ser aplicada em dois dias, com uma redação dissertativoargumentativa e 180 questões de múltipla escolha, das quais 45 são de ciências da natureza e suas tecnologias. 
Após dez anos dessa reestruturação a prova manteve o seu formato em $2019^{6}$ e aumentou consideravelmente o número de instituições que a utiliza em seu processo seletivo, seja em substituição ao vestibular ou como uma das etapas da seleção. A análise das questões da prova de ciências da natureza e suas tecnologias do Enem 20197, sob a ótica das categorias de Shen (1975) e das visões conflitantes de ensino de ciências observadas por Roberts (2007), revela que apenas três delas tinham foco em temas sociais que os estudantes provavelmente encontrarão em suas vidas como consumidores e cidadãos, sendo duas delas ligadas ao letramento prático e uma ligada ao letramento cívico.

Quadro 1 -

Classificação das questões de ciências da natureza pelo foco.

\begin{tabular}{|l|c|c|}
\hline \multicolumn{1}{|c|}{ Roberts (2007) } & Shen (1975) & Enem 2019 \\
\hline Foco em temas sociais & Letramento prático & 2 questões \\
\cline { 2 - 3 } ligados a C\&T & Letramento cívico & 1 questão \\
\hline Foco na ciência em si & Letramento cultural & 42 questões \\
\hline
\end{tabular}

Fonte: autor.

É importante salientar que a classificação acima é baseada no foco da questão, ou seja, no conhecimento esperado pelo avaliador para que o estudante acertasse a questão. Isso porque as aulas do ensino médio, predominantemente voltadas para preparar os estudantes para acertar o maior número possível de questões em processos seletivos para o ensino superior, também têm seu foco no conhecimento que é cobrado nesse tipo de prova. Como se verá adiante questões com foco na ciência em si podem apresentar um tema social de maneira secundária, ou seja, o conhecimento do tema social não influi no acerto da questão.

A seguir apresentaremos comentários acerca das três questões da prova de ciências da natureza do Enem 2019 com foco em temas sociais e de uma amostra ${ }^{8}$ de doze questões com foco na ciência em si, sendo seis delas com um tema social secundário e as outras seis sem tema social secundário.

\section{Foco em temas sociais: letramentos prático e cívico}

Quadro 2 -

Questão 92 da prova de ciências da natureza e suas tecnologias do Enem $2019^{9}$.

Atualmente, uma série de dietas alimentares têm sido divulgadas com os mais diferentes propósitos: para emagrecer, para melhorar a produtividade no trabalho e até mesmo dietas que rejuvenescem o cérebro. No entanto, poucas têm embasamento

${ }^{6}$ A edição de 2019 do Enem foi escolhida para análise neste trabalho por ser a mais recente disponível no site do Inep no período em que esta pesquisa se iniciou.

7 Para este estudo utilizou-se a prova do caderno azul, aplicado no segundo dia do exame.

8 Por questão de espaço não é possível contemplar todas as 45 questões neste artigo.

${ }^{9} \mathrm{Em}$ todas as questões apresentadas a resposta correta, de acordo com gabarito oficial disponível no site do Inep, está em negrito.

Regae: Rev. Gest. Aval. Educ. 
científico, e o consenso dos nutricionistas é que deve ser priorizada uma dieta balanceada, constituída de frutas e vegetais, uma fonte de carboidrato, uma de ácido graxo insaturado e uma de proteína. O quadro apresenta cinco dietas com supostas fontes de nutrientes.

Supostas fontes de nutrientes de cinco dietas

\begin{tabular}{|l|l|l|l|}
\hline Dieta & Carboidrato & Ácido graxo insaturado & Proteína \\
\hline 1 & Azeite de oliva & Peixes & Carne de aves \\
\hline 2 & Carne de aves & Mel & Nozes \\
\hline 3 & Nozes & Peixes & Mel \\
\hline 4 & Mel & Azeite de oliva & Carne de aves \\
\hline 5 & Mel & Carne de boi & Azeite de oliva \\
\hline
\end{tabular}

A dieta que relaciona adequadamente as fontes de carboidrato, ácido graxo insaturado e proteína é a
A) 1 .
B) 2 .
C) 3 .
D) 4 .
E) 5 .

Fonte: http://portal.inep.gov.br/provas-e-gabaritos

Essa questão envolve o letramento prático em ciência, com conhecimentos sobre saúde e alimentação. Todos os estudantes, em sua vida adulta, encontrarão como consumidores a situação de escolha entre ter ou não uma dieta balanceada, em termos de nutrientes, para si mesmos ou para intergrantes de sua família. No entanto, o conhecimento prático envolvido na questão acima alcançaria um público bem maior se o azeite de oliva fosse apresentado como exemplo de alimento com gordura insaturada, ao invés de ácido graxo insaturado. Um dos exemplos de contextualização do conhecimento científico envolvendo situações cotidianas apontados por estudos sobre ensino CTS é a leitura de rótulos de alimentos (Santana; Bastos; Teixeira, 2015; Wartha; Silva; Bejarano, 2013). A expressão que aparece no rótulo do azeite de oliva é gordura insaturada e não ácido graxo.

\section{Quadro 3 -}

Questão 127 da prova de ciências da natureza e suas tecnologias do Enem 2019.

As fêmeas do mosquito da dengue, Aedes aegypti, têm um olfato extremamente refinado. Além de identificar as coleções de águas para oviposição, elas são capazes de detectar de forma precisa e eficaz a presença humana pela interpretação de moléculas de odor eliminadas durante a sudorese. Após perceber o indivíduo, voam rapidamente em direção à fonte alimentar, iniciando o repasto sanguíneo durante o qual podem transmitir o vírus da dengue. Portanto, o olfato desempenha um papel importante para a sobrevivência dessa espécie.

GUIDOBALDI, F.; MAY-CONCHA, I. J.; GUERENSTEIN, P. G. Morphology and Physiology of the Olfactory System of Blood-Feeding Insects. Journal of PhysiologyParis, n. 2-3, abr.-jun. 2014 (adaptado). 
Medidas que interferem na localização do hospedeiro pelo vetor por meio dessa modalidade sensorial incluem a

A) colocação de telas nas janelas.

B) eliminação de locais de oviposição.

C) instalação de borrifadores de água em locais abertos.

D) conscientização para a necessidade de banhos diários.

E) utilização de cremes ou pomadas com princípios ativos.

Fonte: http://portal.inep.gov.br/provas-e-gabaritos.

Trata-se de uma questão envolvendo letramento prático em ciência, relacionada à conhecimentos que podem ser usados no cotidiano para lidar com um problema de saúde. Um dos conhecimentos esperados pelos avaliadores é a função de um repelente: enganar o olfato refinado da fêmea do mosquito. Outro conhecimento esperado, sem o qual o estudante pode se confundir ao escolher a resposta, é o significado de hospedeiro e de vetor, embora a leitura do enunciado como um todo permita a dedução pelo contexto. Também é provável que se esperasse o conhecimento do que vem a ser princípio ativo. O problema é que os repelentes não são apenas cremes e pomadas, mas também sprays líquidos.

Essa questão ilustra uma diferença típica entre um texto acadêmico adaptado para o contexto escolar, seja em avaliações como os vestibulares e o Enem, seja em livros didáticos, e um texto jornalístico que poderia abordar o mesmo tema visando atingir a um público amplo. Uma adaptação jornalística do texto acima poderia substituir, por exemplo, "coleções de águas para oviposição" por "locais de água parada onde elas depositam seus ovos"; "durante a sudorese" por "no suor"; "iniciando o repasto sanguíneo durante o qual podem transmitir o vírus da dengue" por "e enquanto sugam o sangue humano, podem transmitir o vírus da dengue". Além disso, o texto jornalístico daria ênfase especial à necessidade de eliminação de locais com água parada.

\section{Quadro 4 -}

Questão 120 da prova de ciências da natureza e suas tecnologias do Enem 2019.

Em 2014 iniciou-se em São Paulo uma séria crise hídrica que também afetou o setor energético, agravada pelo aumento do uso de ar-condicionado e ventiladores. Com isso, intensifica-se a discussão sobre a matriz energética adotada nas diversas regiões do país. Sendo assim, há necessidade de se buscarem fontes alternativas de energia renovável que impliquem menores impactos ambientais. Considerando essas informações, qual fonte poderia ser utilizada?

A) Urânio enriquecido.

B) Carvão mineral.

C) Gás natural.

D) Óleo diesel.

E) Biomassa.

Fonte: http://portal.inep.gov.br/provas-e-gabaritos. 
Embora o enunciado dessa questão não explicite, o tema da escolha das fontes de energia usadas no país é um típico exemplo de política pública com componentes científicos e tecnológicos. Trata-se de letramento cívico em ciência. Tanto os gestores responsáveis pelas tomadas de decisão na escolha das fontes de energia, quanto o cidadão participativo que se posiciona a favor ou contra as decisões de seus representantes políticos precisam pesar na balança os benefícios e os riscos de cada uma das opções de escolha. Para isso não precisam de um conhecimento aprofundado sobre os processos químicos envolvidos no uso de um recurso natural para gerar energia. A ciência já sabe as vantagens e desvantagens de cada uma das opções listadas na questão que incluem, além do impacto ambiental, os custos de construção e manutenção de uma usina, que varia de uma fonte para outra. $O$ estudante e o cidadão precisam conhecer apenas quais são essas vantagens e desvantagens para se posicionar. A vantagem da biomassa, cobrada na questão, é o fato de ser renovável.

\section{Foco na ciência em si: letramento cultural}

Quadro 5 -

Questão 91 da prova de ciências da natureza e suas tecnologias do Enem 2019.

O curling é um dos esportes de inverno mais antigos e tradicionais. No jogo, dois times com quatro pessoas têm de deslizar pedras de granito sobre uma área marcada de gelo e tentar colocá-las o mais próximo possível do centro. A pista de curling é feita para ser o mais nivelada possível, para não interferir no decorrer do jogo. Após o lançamento, membros da equipe varrem (com vassouras especiais) o gelo imediatamente à frente da pedra, porém sem tocá-la. Isso é fundamental para o decorrer da partida, pois influi diretamente na distância percorrida e na direção do movimento da pedra. Num lançamento retilíneo, sem a interferência dos varredores, verifica-se que o módulo da desaceleração da pedra é superior se comparado à desaceleração da mesma pedra lançada com a ação dos varredores.

Disponível em: http://cbdg.org.br. Acesso em: 29 mar. 2016 (adaptado).

A menor desaceleração da pedra de granito ocorre porque a ação dos varredores diminui o módulo da

A) força motriz sobre a pedra.

B) força de atrito cinético sobre a pedra.

C) força peso paralela ao movimento da pedra.

D) força de arrasto do ar que atua sobre a pedra.

E) força de reação normal que a superfície exerce sobre a pedra.

Fonte: http://portal.inep.gov.br/provas-e-gabaritos.

Essa questão envolve o letramento cultural em ciência e tem seu foco na ciência em si e não em tema social com algum componente científico ou tecnológico que os estudantes provavelmente encontrarão em suas vidas. Mesmo que esse esporte, especificamente, possa ser considerado uma prática social, o conhecimento exigido na questão não envolve uma tomada de decisão. Além disso é plausível supor que apenas uma pequena parcela dos estudantes vai ter contato com o curling, seja como espectador ou como praticante, por se tratar de um esporte praticado no gelo e vivermos num país tropical, pela falta de tradição de esportes de inverno no Brasil e, consequentemente, a 
ausência de ícones vencedores que atraiam novos espectadores e praticantes. Trata-se de uma mera ilustração de situação envolvendo a força de atrito no movimento de um corpo.

Esse tema poderia ser abordado numa situação de relevância social, como os riscos de acidente de trânsito em pistas molhadas, nos dias de chuva, com a redução do atrito dos pneus dos veículos com o asfalto. Essa abordagem é feita numa das questões da pesquisa sobre o indicador de letramento científico da população com 15 anos ou mais, com no mínimo quatro anos de estudos e residente em regiões metropolitanas do Brasil (IBLC, 2014; Serrao et al., 2016), cuja resposta requeria o conhecimento sobre a função das estrias dos pneus para escoamento da água e o perigo de transitar com pneus sem estrias, popularmente conhecidos como pneus carecas.

\section{Quadro 6 -}

Questão 93 da prova de ciências da natureza e suas tecnologias do Enem 2019.

Um pesquisador observou, numa árvore, um ninho de uma espécie de falcão. Apenas um filhote apresentava uma coloração típica de penas de ambos os pais. Foram coletadas amostras de DNA dos pais e filhotes para caracterização genética dos alelos responsáveis pela coloração das penas. O perfil de bandas obtido para cada indivíduo do ninho para os lócus 1 e 2, onde se localizam os genes dessa característica, está representado na figura.

\section{Padrões de bandas em gel das moléculas de DNA dos indivíduos}

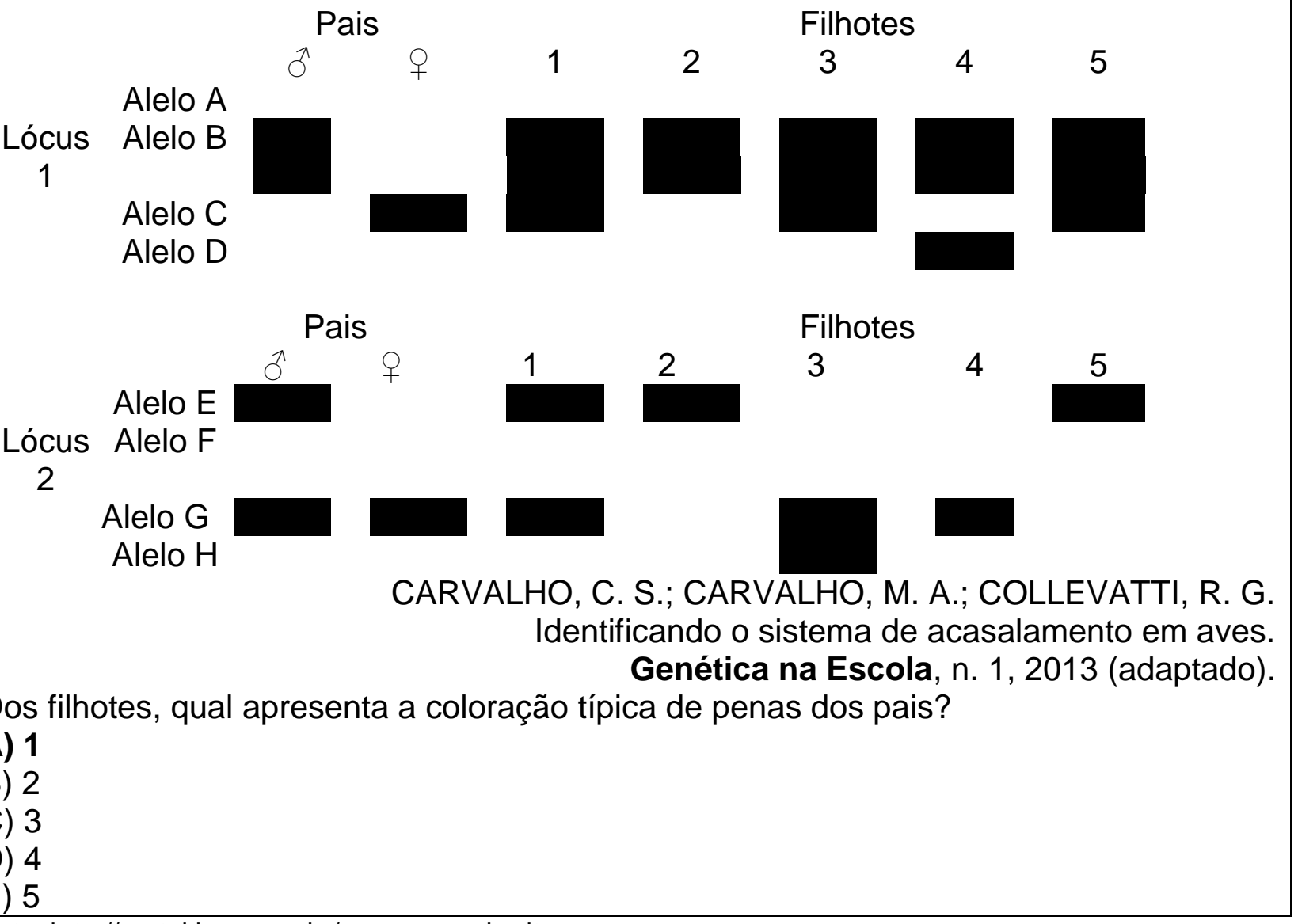

Fonte: http://portal.inep.gov.br/provas-e-gabaritos. 
Embora a resposta para essa questão possa ser encontrada com uma leitura atenta do enunciado e da figura, ela é um exemplo típico de questão que envolve apenas o letramento cultural em ciência, com seu foco na ciência em si, já que não há a abordagem de nenhum tema social com algum componente científico ou tecnológico que os estudantes provavelmente encontrarão em suas vidas. Pensando num ensino que seja voltado não apenas para o futuro biólogo, médico ou profissional de alguma atividade que envolva a genética, trata-se de um conhecimento que pode apenas ampliar o repertório cultural do estudante, caso ele se interesse pelo tema, não tendo influência alguma em suas tomadas de decisão como consumidor ou cidadão. Além disso, assim como as pessoas podem apreciar um determinado gênero de música e não outro, um determinado gênero de filme e não outro, um determinado gênero literário e não outro, não se pode esperar que todos os estudantes apreciem da mesma forma esse tipo de conhecimento.

\section{Quadro 7 -}

Questão 95 da prova de ciências da natureza e suas tecnologias do Enem 2019.

Algumas espécies de orquídeas apresentam flores que mimetizam vespas fêmeas, de
forma que vespas machos são atraídas na tentativa de acasalamento. Ao chegarem às
flores, os machos frequentemente entram em contato com o pólen da flor, sem prejuízo
de suas atividades. Contudo, como não conseguem se acasalar, esses machos
procuram novas fêmeas, podendo encontrar novas flores e polinizá-las.
Essa interação ecológica pode ser classificada como
A) comensalismo.
B) amensalismo.
C) mutualismo.
D) parasitismo.
E) simbiose.

Fonte: http://portal.inep.gov.br/provas-e-gabaritos.

Este é outro exemplo de questão com foco na ciência em si e relacionada ao letramento cultural em ciência, não envolvendo nenhum tema social que os estudantes provavelmente encontrarão em suas vidas. A resposta esperada envolve única e exclusivamente a já tão criticada - nas pesquisas sobre ensino de ciências memorização, nesse caso específico, de um termo usado para classificar uma interação ecológica. Mesmo do ponto de vista cultural é bem mais fácil reter, ao longo da vida, a interação apresentada no enunciado do que sua classificação, esperada na resposta.

Um detalhe ligado ao vocábulo da resposta esperada pelos avaliadores é a apropriação e adaptação que a ciência faz de termos já existentes e usados em outros contextos. Comensalismo deriva de comensal que significa, originalmente, cada um dos que comem juntos e, por extensão, indivíduo que frequenta e come na casa de outro, popularmente conhecido como bicão. O problema é que o bicão também é chamado de parasita, pois vive à custa do outro e isso poderia levar a uma confusão com o parasitismo que aparece como uma das opções erradas de resposta à questão. Como se trata de letramento cultural uma aula sobre esse tema poderia apresentar a explicação para a escolha que a ciência faz de um determinado termo ou a lógica de sua adaptação. Porém, não há razão plausível para requerer este tipo de conhecimento de quem não vai trabalhar futuramente com pesquisa envolvendo interações ecológicas.

\begin{tabular}{|l|l|l|l|l|}
\hline Regae: Rev. Gest. Aval. Educ. & Santa Maria & v. 10 & n. 19 & e64033 p. 1-22
\end{tabular} 2021 
Quadro 8 -

Questão 96 da prova de ciências da natureza e suas tecnologias do Enem 2019.

Na perfuração de uma jazida petrolífera, a pressão dos gases faz com que o petróleo jorre. Ao se reduzir a pressão, o petróleo bruto para de jorrar e tem de ser bombeado. No entanto, junto com o petróleo também se encontram componentes mais densos, tais como água salgada, areia e argila, que devem ser removidos na primeira etapa do beneficiamento do petróleo.

A primeira etapa desse beneficiamento é a
A) decantação.
B) evaporação.
C) destilação.
D) floculação.
E) filtração.

Fonte: http://portal.inep.gov.br/provas-e-gabaritos.

Essa questão não envolve nenhum tema social que os estudantes provavelmente encontrarão em suas vidas. O foco dela está num processo de separação de componentes que são extraídos junto com o petróleo quando se perfura uma jazida, ou seja, o foco está na ciência em si, incluindo seus processos. Não há, nem mesmo secundariamente, uma alusão aos benefícios do petróleo - incluindo toda a cadeia econômica ligada ao uso de seus derivados como matéria-prima - e a seus riscos, como os danos ambientais causados pela queima de combustíveis derivados dessa fonte e o fato de não ser um recurso renovável.

Para que o conhecimento científico requerido nessa questão não fosse meramente ilustrado por um exemplo genérico como o do beneficiamento do petróleo, seria preciso encontrar uma situação da vida real dos estudantes em que eles tivessem que lidar com o problema da separação de componentes e usar o processo da decantação para isso. Porém, os educadores que se filiam à visão de letramento científico com foco na ciência em si, tanto no campo de pesquisas de ensino de ciências, quanto nas políticas públicas de diretrizes curriculares e avaliação de ensino, estão interessados em mostrar como a ciência atua para solucionar um problema em benefício da humanidade. O que importa, nessa visão, é a imagem positiva da ciência e não uma discussão sobre modelos de desenvolvimento científico e tecnológico como aqueles em que o petróleo é protagonista e exerce papel fundamental na economia e na geopolítica global. Esse tipo de visão, se não incluir um debate sobre vantagens e desvantagens do petróleo, não contribui para a formação da cidadania.

\section{Quadro 9 -}

Questão 100 da prova de ciências da natureza e suas tecnologias do Enem 2019. Uma das formas de se obter energia elétrica é usar uma lente convergente circular para concentrar os raios de sol num único ponto, aquecendo um dispositivo localizado nesse ponto a uma temperatura elevada. Com a transformação da energia luminosa em energia térmica, pode ser criado vapor-d'água que moverá uma turbina e gerará energia elétrica. Para projetar um sistema de geração de energia elétrica, a fim de alimentar um chuveiro elétrico de $2.000 \mathrm{~W}$ de potência, sabe-se que, neste local, a energia recebida 
do Sol é $1.000 \mathrm{~W} / \mathrm{m}^{2}$. Esse sistema apresenta taxa de eficiência de conversão em energia elétrica de $50 \%$ da energia solar incidente. Considere $\sqrt{\pi}=1,8$.

Qual deve ser, em metro, o raio da lente para que esse sistema satisfaça aos requisitos do projeto?
A) 0,28
B) 0,32
C) 0,40
D) 0,80
E) 1,11

Fonte: http://portal.inep.gov.br/provas-e-gabaritos.

Essa questão tem foco na ciência em si, envolvendo uma combinação de conhecimentos de ótica e termodinâmica e não apresenta, nem mesmo secundariamente, um tema social com o qual os estudantes possam se deparar em suas vidas. A formação dos estudantes como cidadãos poderia ser explorada numa questão como essa, caso o uso de lente convergente para geração de energia elétrica a partir dos raios do sol fosse apresentado como uma fonte alternativa em relação às outras fontes que compõem a matriz energética.

Do ponto de vista do cidadão a informação mais relevante não é como se faz o cálculo para se projetar um sistema de geração de energia elétrica a partir de uma lente convergente - privilegiada pelo cientista que elaborou a questão - e sim o custo de produção de um sistema como esse em comparação com um sistema que utiliza células fotovoltaicas para gerar energia a partir da luz solar. Os custos, riscos e benefícios dessas e de outras fontes de energia são conhecimentos relevantes para o cidadão se posicionar em relação às políticas públicas que definem a composição da matriz energética do país e o investimento em novas usinas.

\section{Quadro 10 -}

Questão 106 da prova de ciências da natureza e suas tecnologias do Enem 2019.

Astrônomos medem a velocidade de afastamento de galáxias distantes pela detecção
da luz emitida por esses sistemas. A Lei de Hubble afirma que a velocidade de
afastamento de uma galáxia (em $\mathrm{km} / \mathrm{s})$ é proporcional à sua distância até a Terra,
medida em megaparsec (Mpc). Nessa lei, a constante de proporcionalidade é a
constante de Hubble $\left(\mathrm{H}_{0}\right)$ e seu valor mais aceito é de $72(\mathrm{~km} / \mathrm{s}) / \mathrm{Mpc}$. O parsec $(\mathrm{pc})$ é
uma unidade de distância utilizada em astronomia que vale aproximadamente $3 \times 10^{16}$
$\mathrm{~m}$. Observações astronômicas determinaram que a velocidade de afastamento de uma
determinada galáxia é de $1.440 \mathrm{~km} / \mathrm{s}$.
Utilizando a Lei de Hubble, pode-se concluir que a distância até essa galáxia, medida
em km, é igual a:
A) $20 \times 10^{0}$
B) $20 \times 10^{6}$
C) $6 \times 10^{20}$
D) $6 \times 10^{23}$
E) $6 \times 10^{26}$

Fonte: http://portal.inep.gov.br/provas-e-gabaritos. 
Essa questão é um exemplo típico de letramento cultural em ciência. No entanto, para apreciar o tema da astronomia e do estudo das galáxias o estudante, ou qualquer pessoa leiga, pode assistir a séries de TV como Cosmos, idealizada pelo astrônomo Carl Sagan em 1980 e reformulada em nova versão em 2014, sem precisar, para isso, saber calcular a distância de uma galáxia em relação à Terra. Além disso, não há nenhuma situação com a qual os estudantes vão se deparar em suas vidas, como consumidores e cidadãos, em que eles precisem usar o conhecimento sobre a Lei de Hubble e o cálculo da distância de uma galáxia.

O próprio letramento cultural em ciência pode ser mais bem sucedido, em termos de despertar o interesse do estudante ou do público leigo por um conhecimento sofisticado como o da astronomia, se o foco estiver, por exemplo, na relação entre uma ciência básica que estuda o comportamento da luz no espaço e uma ciência aplicada que gera produtos como o controle remoto de TV baseada em conhecimentos gerados décadas antes por uma ciência básica. $O$ foco num processo da ciência, como o cálculo da distância de uma galáxia, tem pouca chance de despertar o interesse de um estudante que não tenha planos futuros relacionados com a astrofísica.

Quadro 11 -

Questão 94 da prova de ciências da natureza e suas tecnologias do Enem 2019.

Algumas moedas utilizam cobre metálico em sua composição. Esse metal, ao ser
exposto ao ar úmido, na presença de $\mathrm{CO}_{2}$, sofre oxidação formando o zinabre, um
carbonato básico de fórmula $\mathrm{Cu}_{2}(\mathrm{OH})_{2} \mathrm{CO}_{3}$, que é tóxico ao homem e, portanto,
caracteriza-se como um poluente do meio ambiente. Com o objetivo de reduzir a
contaminação com o zinabre, diminuir o custo de fabricação e aumentar a durabilidade
das moedas, é comum utilizar ligas resultantes da associação do cobre com outro
elemento metálico.
A propriedade que o metal associado ao cobre deve apresentar para impedir a
formação de zinabre nas moedas é, em relação ao cobre,
A) maior caráter ácido.
B) maior número de oxidação.
C) menor potencial de redução.
D) menor capacidade de reação.
E) menor número de elétrons na camada de valência.

Fonte: http://portal.inep.gov.br/provas-e-gabaritos.

Essa questão é ilustrativa de um determinado tipo de visão dos avaliadores, de muitos pesquisadores da área de ensino de ciências e de diversos professores das disciplinas das ciências naturais: é preciso mostrar aos estudantes exemplos de problemas enfrentados pela humanidade ao longo de sua história e soluções encontradas pela ciência para resolver esses problemas: reduzir a contaminação, diminuir o custo de fabricação e aumentar a durabilidade das moedas. Mais uma vez trata-se de letramento em ciência do tipo cultural e o objetivo implícito é a valorização da ciência e do seu papel para o bem da humanidade. 
No entanto é importante frisar que, embora o enunciado da questão mencione um poluente do meio ambiente, não se trata de uma situação com a qual os estudantes vão se deparar ao longo de suas vidas, pois o problema já foi solucionado. Ou seja, não se trata de algo que possa demandar a participação deles como consumidores ou cidadãos, não envolve um problema ambiental da sua comunidade que pudesse demandar uma petição coletiva para o poder público. Para destacar o que vem a ser, de fato, participação cidadã, Rodrigues (2010) apresenta um exemplo de ensino CTS envolvendo o estudo sobre a qualidade da água da Lagoa da Pampulha, em Belo Horizonte, e a participação dos estudantes em audiência pública para apresentação dos problemas e cobrança de solução por parte das autoridades.

$\mathrm{Na}$ análise da prova de 2009 do Enem Miranda et al. (2011) concluíram que a contextualização, na maioria das questões, apenas ilustrava o conhecimento científico e não levava o estudante a pensar em si mesmo como um potencial transformador da realidade. Um dos equívocos de quem defende um ensino de ciências com foco na ciência em si é supor que os estudantes poderão aprender, com esses exemplos genéricos de soluções de problemas, a resolver qualquer tipo de situação-problema com a qual se deparar ao longo da vida.

\section{Quadro 12 -}

Questão 105 da prova de ciências da natureza e suas tecnologias do Enem 2019.

O nitrogênio é essencial aos seres vivos e pode ser adquirido pelas plantas, através da absorção pelas raízes, e pelos animais, através da alimentação. Sua utilização na agricultura de forma inadequada tem aumentado sua concentração no ambiente, e o excesso, que é transportado para os cursos-d'água, tem causado a eutrofização. Contudo, tal dano ambiental pode ser minimizado pela adoção de práticas sustentáveis, que aprisionam esse elemento no solo, impedindo seu escoamento para rios e lagos.

O método sustentável visando a incorporação desse elemento na produção, prevenindo tal dano ambiental, é o(a)

A) adição de minhocas na terra.

B) irrigação da terra antes do plantio.

C) reaproveitamento do esterco fresco.

D) descanso do solo sem adição de culturas.

E) fixação biológica nas raízes por bactérias.

Fonte: http://portal.inep.gov.br/provas-e-gabaritos.

O foco dessa questão está na ciência em si, na solução científica para um problema ambiental causado por práticas inadequadas na agricultura. Embora os estudantes, enquanto possíveis consumidores de peixes de água doce, possam ser potencialmente afetados por uma concentração excessiva de nitrogênio em rios e lagos, esse tema social é secundário na questão e não é requerida uma reflexão sobre a prática que gerou o problema. Segundo Ayala (1996) o que se espera com o letramento científico é que as pessoas saibam que nem toda intervenção na natureza é só benéfica ou só maléfica e 
que a solução para um problema econômico, como a produção agrícola, pode gerar outro problema social ou ambiental. Ele apresenta como exemplo disso as usinas nucleares e as usinas a carvão para geração de energia, cada qual com sua lista de riscos e benefícios.

\title{
Quadro 13 -
}

Questão 107 da prova de ciências da natureza e suas tecnologias do Enem 2019.

\begin{abstract}
Segundo o pensamento religioso de Padre Cícero Romão Batista (1844-1934), a ação humana do camponês sobre a natureza deveria seguir alguns princípios norteadores, os quais ficaram conhecidos na cultura popular brasileira como "os preceitos ecológicos do Padre Cícero". Dentre esses preceitos, destaca-se: "Não plante em serra acima, nem faça roçado em ladeira muito em pé: deixe o mato protegendo a terra para que a água não a arraste e não se perca a sua riqueza."
\end{abstract}

FIGUEIREDO, J. B. A. Educação ambiental dialógica: as contribuições de Paulo freire e a cultura popular nordestina. Fortaleza: UFC, 2007.

Comparando o pensamento do padre Cícero com o atual conhecimento científico, podese encontrar elementos de convergência, já que a prática citada contribui primariamente para evitar (o)a
A) erosão.
B) salinização.
C) eutrofização.
D) assoreamento.
E) desertificação.

Fonte: http://portal.inep.gov.br/provas-e-gabaritos.

Pode-se supor que um problema que afeta diretamente a natureza pela ação humana e, indiretamente afeta ao próprio ser humano, seja considerado algo ligado à realidade do estudante. No entanto estudantes que não trabalharão com agricultura só irão se deparar com esse problema caso leiam uma reportagem sobre erosão causada por prática de plantio inadequada, assim como poderia ler sobre engenharia genética ou sobre exploração espacial, o que se configura como letramento cultural em ciência. $O$ foco é na ciência em si e sua explicação para um fenômeno causado pela ação humana.

Uma possibilidade de abordar o tema da questão do ponto de vista social, visando ao letramento cívico em ciência, seria associar o problema da erosão a uma discussão política mais ampla, como a do Código Florestal, mostrando os interesses envolvidos no posicionamento favorável ou contrário a cada item da lei e pesando na balança das decisões as consequências econômicas e ambientais da mudança na legislação. No caso específico dos preceitos ecológicos do padre Cícero poderia ser apresentada alguma iniciativa de educação ambiental, como política pública diante da qual o estudante e cidadão pudesse se posicionar. 
Quadro 14 -

Questão 110 da prova de ciências da natureza e suas tecnologias do Enem 2019.

Um laudo de análise de laboratório apontou que amostras de leite de uma usina de beneficiamento estavam em desacordo com os padrões estabelecidos pela legislação. Foi observado que a concentração de sacarose era maior do que a permitida.

Qual teste listado permite detectar a irregularidade descrita?

A) Medida da turbidez.

B) Determinação da cor.

C) Determinação do $\mathrm{pH}$.

D) Medida da densidade.

E) Medida da condutividade.

Fonte: http://portal.inep.gov.br/provas-e-gabaritos.

O foco dessa questão é o conhecimento do tipo de teste usado para detectar uma irregularidade na produção de usinas de beneficiamento de leite. Uma possibilidade de estudantes genéricos se depararem com esse tipo de problema em suas vidas futuras como consumidores e cidadãos seria ler uma reportagem sobre irregularidade detectada em determinada usina. No Estado de São Paulo a fiscalização de usinas de beneficiamento de leite compete ao Serviço Sanitário, por intermédio da Inspetoria de Fiscalização do Leite e Laticínios. Antes de chegar aos pontos de venda para o consumidor todo produto alimentício de origem animal tem que passar pela avaliação do Serviço de Inspeção Federal, um sistema do Ministério da Agricultura, Pecuária e Abastecimento para controle da qualidade na produção de alimentos. Portanto, se não for trabalhar futuramente em Serviço Sanitário ou Inspeção Federal o estudante não precisa saber qual teste seria usado para detectar uma concentração de sacarose no leite maior que a permitida por lei. Poderia entender uma reportagem sobre o assunto sem ter esse tipo de conhecimento técnico.

Quadro 15 -

Questão 119 da prova de ciências da natureza e suas tecnologias do Enem 2019.

As algas são uma opção sustentável na produção de biocombustível, pois possuem estrutura simples e se reproduzem mais rapidamente que os vegetais, além da grande capacidade de absorverem dióxido de carbono. Esses organismos não são constituídos por tecidos heterogêneos, entretanto, assim como os vegetais, possuem parede celular.

Algas podem substituir metade do petróleo e inaugurar química verde (Agência Fapesp, 16/08/2010). Disponível em: www.inovacaotecnologica.com.br. Acesso em: 1 ago. 2012 (adaptado).

Para obtenção de biocombustível a partir de algas e vegetais, é necessário utilizar no processo a enzima
A) amilase.
B) maltase.
C) celulase.
D) fosfatase.
E) quitinase.

Fonte: http://portal.inep.gov.br/provas-e-gabaritos. 
Essa questão é um exemplo do que Alves (2011) chamou de mera ilustração na contextualização do conhecimento científico. Embora seja mencionado no enunciado um tema social importante - a opção sustentável na produção de biocombustível -, o conhecimento necessário para acertar a resposta é centrado num processo científico, ou seja, na ciência em si, e não no tema social no qual a ciência tem um papel relevante. Por isso trata-se de letramento cultural em ciência, pois os estudantes que não tiverem intenção de seguir uma carreira científica, para tomarem decisões como consumidores e cidadãos em relação a esse tema, não precisam saber qual enzima é utilizada no processo de obtenção de biocombustível a partir de algas. O que precisam saber são os benefícios e os riscos dos combustíveis derivados do petróleo e as vantagens das algas como fontes alternativas.

A questão também ilustra uma diferença entre o texto jornalístico e o texto produzido por um cientista no papel de avaliador dos conhecimentos dos estudantes do ensino médio. Para o jornalista da Agência Fapesp, que elaborou a notícia, a informação mais relevante a ser dada para o público deve aparecer no título: as algas podem substituir o petróleo e inaugurar a química verde. Para o cientista o mais importante é o processo usado para se chegar a esse resultado. É o que Gomes (2002) chamou de reverso da estrutura do texto científico no texto de divulgação científica: "no jornalismo científico procura-se a relevância nas conclusões das pesquisas e na aplicação de seus resultados no cotidiano das pessoas" e não "os materiais e os métodos utilizados no trabalho" ( $p$. 104). Isso não significa que a enzima não possa aparecer num texto jornalístico, mas não é tão relevante para o público que o jornalista pretende atingir quanto a possibilidade de substituição do petróleo por uma fonte alternativa. A propósito, as palavras enzima e celulase não aparecem na matéria originalmente pela Agência Fapesp ${ }^{10}$.

\section{Quadro 16 -}

Questão 129 da prova de ciências da natureza e suas tecnologias do Enem 2019.

O etanol é um combustível renovável obtido da cana-de-açúcar e é menos poluente do que os combustíveis fósseis, como a gasolina e o diesel. $O$ etanol tem densidade 0,8 $\mathrm{g} / \mathrm{cm}^{3}$, massa molar $46 \mathrm{~g} / \mathrm{mol}$ e calor de combustão aproximado de $-1300 \mathrm{~kJ} / \mathrm{mol}$. Com o grande aumento da frota de veículos, tem sido incentivada a produção de carros bicombustíveis econômicos, que são capazes de render até $20 \mathrm{~km} / \mathrm{L}$ em rodovias, para diminuir a emissão de poluentes atmosféricos.

O valor correspondente à energia consumida para que o motorista de um carro econômico, movido a álcool, percorra $400 \mathrm{~km}$ na condição de máximo rendimento é mais próximo de
A) $565 \mathrm{MJ}$.
B) $452 \mathrm{MJ}$.
C) $520 \mathrm{~kJ}$.
D) $390 \mathrm{~kJ}$.
E) $348 \mathrm{~kJ}$.

Fonte: http://portal.inep.gov.br/provas-e-gabaritos.

10 Disponível em https://www.inovacaotecnologica.com.br/noticias/noticia.php?artigo=algas-substituirpetroleo-quimica-verde. 
O enunciado desta questão inicia com uma informação socialmente relevante, o fato de o etanol ser um combustível renovável e menos poluente que a gasolina e o diesel. No entanto, o foco da questão está no cálculo do consumo de energia de um carro movido a álcool durante um determinado percurso e não nas questões socioambientais e econômicas envolvidas no tema das fontes usadas como combustíveis. Essa questão, portanto, é um exemplo de letramento cultural em ciência, pois o conhecimento que o cidadão precisa para tomar uma decisão de escolha sobre o combustível que irá consumir não é saber fazer o cálculo do consumo de energia de um carro movido a álcool.

Além da informação ambiental que aparece no início do enunciado da questão o consumidor geralmente compara quantos quilômetros seu carro percorre com um litro de gasolina e quantos quilômetros percorre com um litro de álcool e, se julgar necessário, faz as contas pelo preço de cada combustível na bomba para decidir qual compensa mais economicamente, caso não queira pesar na balança de sua decisão a questão ambiental. Não é incomum que as escolhas dos consumidores sejam mais pautadas em interesses individuais, como uma determinada gasolina que aumenta o desempenho do motor do seu carro - de acordo com a propaganda de uma bandeira de postos de combustíveis - do que em questões coletivas, como a redução de emissões dos gases causadores do efeito estufa. Discutir essas questões coletivas na escola é fundamental para a construção da cidadania e o Enem poderia dar o exemplo e incentivar essas discussões, caso as colocasse como foco na avaliação.

\section{Conclusão}

É um desafio encontrar um equilíbrio entre um ensino de ciências voltado para a formação de futuros cientistas e engenheiros e aquele voltado para o exercício da cidadania. A defesa de temas sociais como foco e ponto de partida para se abordar ciência e tecnologia não significa excluir do currículo o cânone da ciência, e sim uma mudança na ênfase do ensino para que ele se torne mais significativo para os estudantes e até mesmo para que possa despertar o interesse de um número maior de estudantes para as carreiras científicas. Neste sentido, as provas de acesso ao ensino superior, como os vestibulares e o Enem, são importantes para que essa mudança se concretize e chegue de fato às salas de aula.

\section{Referências}

ALVES, Aline Roberta. Propostas teórico-metodológicas do Enem: relações entre o enfoque CTS/CTSA e o discurso de professores acerca da prática docente. São Carlos, Ufscar, 2011. 125f. Dissertação (Mestrado em Educação). Programa de Pós-Graduação em Educação, Universidade Federal de São Carlos.

AYALA, Francisco José. Introductory essay: the case for scientific literacy. In: MOORE, Howard (ed.). World science report. Paris: Unesco, 1996, p. 1-5.

BRASIL. Constituição da República Federativa do Brasil. Brasília: Senado Federal, 1988.

BRASIL. Lei de diretrizes e bases da educação nacional. Brasília: MEC, 1996.

BRASIL. Parâmetros curriculares nacionais. Brasília: MEC/SEF, 1997. 
CAVALCANTI, Daniele Blanco; COSTA, Marco Antonio Ferreira; CHRISPINO, Álvaro. Educação ambiental e movimento CTS: caminhos para a contextualização do ensino de biologia. Revista Práxis, Volta Redonda, v. 6, n. 12, 2014, p. 27-42.

FERREIRA, Sergio Daniel. Análise das questões do Enem da área de Ciências Naturais pelo enfoque CTS. São Carlos, Ufscar, 2011. 89f. Dissertação (Mestrado em Educação). Programa de Pós-Graduação em Educação, Universidade Federal de São Carlos.

GOMES, Isaltina Maria de Azevedo Mello. A ciência nos jornais. Revista Galáxia, Belo Horizonte, v. 2, n. 3, 2002, p. 93-108.

IBLC. ILC - indicador de letramento científico: sumário executivo de resultados. São Paulo: Fundação Carlos Chagas, 2014.

MASCIO, Carlos César. Exame Nacional do Ensino Médio (Enem): articulações entre a educação ciência, tecnologia e sociedade e a proposta nacional para o ensino de química. São Carlos, Ufscar, 2009. 100f. Dissertação (Mestrado em Educação). Programa de PósGraduação em Educação. Universidade Federal de São Carlos.

MIRANDA, Elisangela Matias et al. Enem 2009: articulações CTS, interdisciplinaridade e contextualização evidenciadas nas questões das Ciências da Natureza. ENCONTRO NACIONAL DE PESQUISA EM EDUCAÇÃO EM CIÊNCIAS, 8, 2011. Anais ... Campinas: Unicamp, 2011. Disponível em http://abrapecnet.org.br/atas enpec/viiienpec/resumos/R0292-1.pdf. Acesso em 01/02/2021.

ROBERTS, Douglas. Scientific literacy/science literacy. In: ABELL, Sandra; LEDERMAN, Nornam (eds.). Handbook of research on science education. New York: Routledge, 2007, p. $729-780$.

RODRIGUES, Clarissa. Abordagem CTS e possibilidades de letramento científico no projeto água em foco: tipos textuais e linguagem científica. Belo Horizonte, UFMG, 2010. 99f. Dissertação (Mestrado em Educação). Programa de Pós-Graduação em Educação, Universidade Federal de Minas Gerais.

SANTANA, Tainam Amorim; BASTOS, Ana Paula Solino; TEIXEIRA, Paulo Marcelo Marini. Nossa alimentação: análise de uma sequência didática estruturada segundo referenciais do Movimento CTS. Revista Brasileira de Pesquisa em Educação em Ciências, Belo Horizonte, v. 15, n. 1, 2015, p. 105-122.

SANTOS, Wildson Luiz Pereira dos. Educação científica na perspectiva de letramento como prática social: funções, princípios e desafios. Revista Brasileira de Educação, Rio de Janeiro, v. 12, n. 36, 2007, p. 474-550.

SANTOS, Wildson Luiz Pereira dos; MORTIMER, Eduardo Fleury. Tomada de decisão para ação social responsável no ensino de ciências. Ciência \& Educação, Bauru, v. 7, n. 1, 2001, p. 95-111.

SANTOS, Wildson Luiz Pereira dos; SCHNETZLER, Roseli Pacheco. Educação em química: compromisso com a cidadania. ljuí: Unijuí, 1997.

SERRAO, Luis Felipe Soares et al. A experiência de um indicador de letramento científico. Cadernos de Pesquisa, São Paulo, v. 46, n. 160, 2016, p. 334-361.

SHEN, Benjamin. Science literacy: public understanding of science is becoming vitally needed in developing and industrialized countries alike. American Scientist, Carolina do Norte, v. 63, n. 3, 1975, p. 265-268. 
WARTHA, Edson José; SILVA, Erivanildo Lopes da; BEJARANO, Nelson Rui Ribas Bejarano. Cotidiano e contextualização no ensino de química. Química Nova na Escola, São Paulo, v. 35, n. 2, 2013, p. 84-91.

Rodrigo Bastos Cunha é professor no Programa de Pós-Graduação em Divulgação Científica e Cultural da Universidade Estadual de Campinas.

Orcid: https://orcid.org/0000-0003-3679-1062.

Endereço: Rua Seis de Agosto, 50, 3o piso - 13083-873 - Campinas - SP - Brasil.

E-mail: rbcunha@unicamp.br.

Critérios de autoria: Rodrigo Bastos Cunha concebeu, individualmente, a ideia, coleta e análise dos dados, a redação e a consolidação do artigo.

Recebido em 1으 de fevereiro de 2021.

Aceito em 24 de maio de 2021.

(c) $(i)(\$)$ 